\title{
Labour market disadvantage, political orientations and voting: how adverse labour market experiences translate into electoral behaviour
}

\author{
Patrick Emmenegger ${ }^{1}$, Paul Marx ${ }^{2}$, and Dominik Schraff ${ }^{1, *}$ \\ ${ }^{1}$ Department of Political Science, University of St. Gallen, St. Gallen CH-9000, Switzerland, and \\ ${ }^{2}$ Department of Political Science, University of Southern Denmark, Odense DK-5230, Denmark \\ *Correspondence: dominik.schraff@unisg.ch
}

\begin{abstract}
How does labour market disadvantage translate into political behaviour? Bringing together the literatures on political alienation, redistribution preferences and insider-outsider politics, we identify three mechanisms by which labour market disadvantages influence voting behaviour. Disadvantages can increase support for redistribution, reduce internal political efficacy or lower external political efficacy. This translates into support for pro-redistribution parties, vote abstention or support for protest parties. Using the Dutch LISS survey, we observe a twin effect of increased support for redistribution and decreased external efficacy. Mediated through redistributive preferences, we find a positive effect of labour market disadvantage on voting for left parties. Mediated through external efficacy we find a positive effect of labour market disadvantage on protest voting. In contrast, we do not find any effect of labour market disadvantage on internal efficacy. Hence, the observed effect of labour market disadvantage on political abstention is entirely mediated by external efficacy.
\end{abstract}

Key words: political behaviour, labour market disadvantage, political efficacy, redistribution, elections, protest voting

JEL classifications: D72, J24, J64

\section{Introduction}

How do negative experiences in the labour market affect individuals' political behaviour? This question has received considerable attention in social science research. With some simplification, one can identify three research traditions dealing with it. First, there are studies (some of them classics) analysing whether the experience of labour market disadvantage, such as unemployment 
or economic insecurity, affect political alienation (Jahoda et al., 1972; Schlozman and Verba, 1979; Rosenstone, 1982; Verba et al., 1995). These studies emphasise sociological and psychological mechanisms linking labour market experiences to political involvement.

Second, political economists typically disregard effects on citizens' involvement, but analyse whether and how labour market disadvantage affects support for redistribution, social protection and left parties (Iversen and Soskice, 2001; Cusack et al., 2006; Rehm, 2009). The underlying theory emphasises economically instrumental motives and how they are determined by individuals' position in the labour market.

Within political economy, one can further distinguish insider-outsider theory as a third approach (Saint-Paul, 1996; Lindbeck and Snower, 2001), which turns the standard expectation of how labour market disadvantage affects voting behaviour upside down. It adds the notion that the post-industrial working class is characterised by political conflict between privileged and disadvantaged workers and that traditional left parties side with the former. The disadvantaged outsiders then realign with other parties or simply abstain from participating (Rueda, 2005; Lindvall and Rueda, 2014).

How do these different theoretical perspectives relate to each other? To date there is surprisingly little dialogue between them. This is unfortunate because they focus on different consequences of labour market disadvantage, which are likely to jointly affect political behaviour. Depending on the context and type of political behaviour one is interested in, alienation from politics and economic interests may reinforce each other or cancel each other out. Hence, researchers risk making erroneous inferences if the causal link connecting labour market disadvantage and political behaviour is not carefully modelled. Only empirical analyses taking into account both alienation and instrumental voting are able to capture the effect of labour market disadvantage on voting behaviour.

Specifically, we argue that whilst some voters repeatedly exposed to labour market disadvantage develop tendencies to support redistribution, others, at the same time, feel less politically efficacious. Using the classic distinction between internal and external political efficacy (Lane, 1959; Balch, 1974; Rosenstone and Hansen, 1993), we formulate three hypotheses about how labour market disadvantage influences voting behaviour. First, labour market disadvantage can depress individuals' self-perceived competence to influence politics (low internal efficacy), which is likely to lead to abstention from voting. Second, labour market disadvantage can influence individuals' perception of the extent to which the political system, in particular the mainstream parties, are responsive to their personal interests (low external efficacy), which is likely to lead to increased protest voting or abstention from voting. Finally, following the political economy literature, we hypothesise that labour market disadvantage influences individuals' economic interests and is thus likely to lead to increased support for pro-redistribution parties.

Considering multiple mechanisms mediating between labour market disadvantage and political behaviour helps theorising party preferences more precisely. Whereas preferences for redistribution and low efficacy pull voters in different directions with regards to some parties (typically the radical right and the mainstream left), both mechanisms reinforce each other in the case of the radical left, which combines the possibility to protest and to support the welfare state. Hence, the main contribution of this article is providing a novel and more encompassing framework for studying how experiences of labour market disadvantage affect political behaviour.

A second contribution of the article is conceptual. Most empirical approaches conceptualise labour market disadvantage by focusing on a single dimension, such as risk, income or 
employment status. However, post-industrial labour markets are increasingly characterised by various forms of labour market disadvantage between which individuals oscillate, such as involuntary part-time, temporary employment or in-work poverty (Emmenegger et al., 2012). Moreover, the existing literature typically relies on cross-sectional measures of labour market disadvantage. Given the resilience of some dimensions of political behaviour (Prior, 2010), it is, however, doubtful whether such a 'snapshot' operationalisation is suitable to capture the effects of labour market experiences (Margalit, 2013). We overcome both shortcomings of the existing literature by using a composite indicator of labour market disadvantage, which includes different forms of disadvantage as well as longitudinal information on the individual level.

We analyse our argument using micro-level data from the Netherlands. It is a perfect test case to go beyond broad left-right distinctions because the Dutch labour market is characterised by various forms of labour market disadvantage and because its multi-party system offers voters remarkable variety in terms of ideological placement. In the Dutch context, we do observe a twin effect of increased support for redistribution and decreased external efficacy. In a mediation analysis we find significant indirect effects of labour market disadvantage on vote choice. Mediated through redistributive preferences, we find a positive effect on voting for left political parties (Greens, Labour and Socialists). Mediated through external efficacy we find a positive effect on protest behaviour (voting for the Socialists and the radical right Freedom Party as well as political abstention). The interplay of both mechanisms explains why the (direct) effect of labour market disadvantage is strongest for voting for the Dutch Socialist Party. In contrast, we do not find any effect of labour market disadvantage on internal efficacy. Hence, the observed effect of labour market disadvantage on political abstention is entirely mediated by external efficacy.

\section{Labour market disadvantage and political behaviour: alienation or economic interests?}

How exactly are experiences of labour market disadvantage and political behaviour connected? In the literature, we find three more or less disparate answers.

First, it has been argued that labour market disadvantage leads to phenomena such as withdrawal from political participation, radicalisation or political distrust. We label this research tradition, which can be traced back to the Marienthal study (Jahoda et al., 1972), the alienation literature. It has traditionally focussed on unemployment as a form of disadvantage that deprives citizens of work-related skills and resources that foster political inclusion (Rosenstone, 1982; Verba et al., 1995; Schur, 2003). A problem with such resource-based arguments is that they are based on theories of employment and its relevance for participation; mechanisms linking disadvantage to participation remain theoretically under-developed (but we try to spell them out in the next section). Recent contributions have included non-standard employment as additional forms of disadvantage and pointed to party agency as the driving force of alienation (King and Rueda, 2008; Standing, 2011)—an argument to which we return later.

Second, political economy postulates that labour market disadvantage strengthens support for redistribution and left parties. Economically instrumental voters respond to disadvantage by voting for parties maximizing redistribution and social protection, that is, the left (Hibbs, 1977; Korpi, 1983; Cusack et al., 2006). That risk, income and unemployment influence political preferences along these lines has been repeatedly confirmed (e.g. Rehm, 2009; Margalit, 
2013). However, political economy is often criticised for omitting non-economic motives (Fong, 2001; Bechtel et al., 2014), and indeed it has mostly neglected mechanisms by which labour market disadvantage may lead to political alienation rather than to pragmatic policy choices. In fact, arguments about limited resources and frustration are difficult to reconcile with assumptions of sophistication and instrumentality.

Adding further complexity, a third approach on disadvantage exists within political economy. Insider-outsider theory adds to standard political economy by insisting that labour market disadvantage is distributed discontinuously. Discontinuities result from labour market institutions, in particular firing costs, hampering mobility prospects of unemployed and non-standard workers (Saint-Paul, 1996; Rueda, 2005). Insider-outsider theory turns the political economy argument on its head: instead of voting for the left (which is supportive of mobility barriers), the disadvantaged turn towards right parties (which support deregulation of mobility barriers), towards the radical left (which promises expanding insider privileges to outsiders) or the extreme right (which allows expressing discontent) (Lindvall and Rueda, 2014, p. 462).

By asking which workers are really represented by left parties, insider-outsider theory challenges the simple link between disadvantage and voting left. Furthermore, bringing representation and party behaviour into the picture has raised awareness amongst scholars that disadvantaged workers may withdraw from politics or radicalise (Rueda, 2005; King and Rueda, 2008; Häusermann and Schwander, 2012; Marx, 2014). However, so far insideroutsider theory has not provided an explicit theoretical argument of how rational responses to labour market disadvantage and risk of alienation are related to each other. It also remains unclear how alienation from mainstream parties is manifested in political behaviour.

To conclude, theories linking political behaviour to labour market disadvantage focus either on instrumental choices of policies and parties or alienation from (mainstream) politics. Insider-outsider theory has affinities to both perspectives, but fails to provide coherent theoretical predictions of political behaviour. Empirical research indicates that both instrumental and alienation arguments have at least some explanatory power. Hence, there is no a priori reason why instrumental motives and political alienation should not jointly affect political behaviour. In the following, we propose a framework integrating both perspectives.

\section{The framework: the effect of labour market disadvantage on voting behaviour}

The literature review has shown that we are confronted with a multitude of plausible but empirically under-explored causal channels whose relations to each other are unclear. Given our lack of empirical knowledge, we think it would be premature to formulate a unified theory of labour market disadvantage and voting at this stage. What we propose instead is a framework that allows integrating diverse perspectives and deriving testable predictions in a given political context. We develop such a framework in two steps by linking disadvantage first to turnout and second to vote choice. Before we do so, we briefly clarify our understanding of disadvantage.

\subsection{What is labour market disadvantage?}

Disadvantage comprises concepts such as employment precariousness, outsiderness, insecurity, in-work poverty and so on. It covers situations such as having no or only insecure employment, being underemployed due to involuntary part-time or earning a low wage. We do not 
claim that these forms yield identical political behaviour effects. But from a psychological and epidemiological perspective, they have in common that they trigger (worries about future) material and social deprivation and hence function as powerful stressors. This has been shown for job insecurity (Sverke et al., 2002), unemployment (Paul and Moser, 2009) and precarious employment (Benach et al., 2014).

Existing political behaviour studies on disadvantage, however, have ignored that negative effects can accumulate if workers oscillate between different forms of disadvantage. Epidemiological research has recognised the importance of the question whether 'the toxic effects of precariousness are cumulative over time' (Benach et al., 2014, p. 243). We think this is equally important for political behaviour because persistence greatly exacerbates the impact of disadvantage(s) on individuals' lives and therefore amplifies the mechanisms discussed below. What follows from this is that disadvantage should be conceptualised as multifaceted phenomenon unfolding over time. This is to distinguish it from isolated and transient job-related problems.

\subsection{Labour market disadvantage and turnout}

Political economy makes various predictions about vote choice of the disadvantaged; the alienation perspective casts doubt on whether they turn out in the first place. What is the mechanism connecting disadvantage to turnout? Consider this simple voting model (to be found in Krosnick et al., 2010) where likelihood of voting is a function of:

(motivation to vote $) \times($ ability to vote $) \times(1-$ difficulty of voting $)$

The model does not include economic benefits of voting, which are zero given vanishingly low chances of affecting election outcomes. Difficulty refers to the convenience of voting procedures, which are exogenous to the labour market situation (and hence irrelevant for us). Motivation and ability, however, could be affected by disadvantage.

To argue why, we propose replacing the abstract concept of alienation with the more concrete concept of (low) political efficacy. Efficacy comprises internal and external political efficacy (Lane, 1959; Balch, 1974). Internal efficacy means subjective ability to make meaningful political decisions. External efficacy means subjective responsiveness of political elites to citizens' demands. Both forms are strong predictors of turnout (Acock et al., 1985; Rosenstone and Hansen, 1993; Ulbig and Funk, 1999). Both could be depressed by labour market disadvantage.

Regarding internal efficacy, one mechanism is based on the spill-over model linking work experiences with political participation (Pateman, 1970; Sobel, 1993; Adman, 2008). Accordingly, if frustrating job experiences lower workers' self-esteem and sense of selfmastery, this can spill over into subjective beliefs about political competences (Greenberg et al., 1996; Schur, 2003). Put simply, feeling like a failure in the labour market may lead to feelings of incompetence with regards to politics. Note that low internal efficacy is similar but not identical with the lack of civic skills conjectured by Verba et al. (1995).

In a similar vein, we think that Rosenstone's (1982) resource argument can be substantiated by relating it to internal efficacy. Being absorbed by job-related concerns may prevent individuals experiencing labour market disadvantages from investing time and cognitive resources into acquiring the necessary information to feel internally efficacious. The intuition here is that the unemployed and insecure rather study vacancy notices in newspapers than 
the politics section. The upshot of both mechanisms (spill-over and limited resources) is that disadvantage translates into lower (subjective or objective) ability to vote, one of the variables in the voting model cited above.

Regarding motivation to vote, the second relevant variable, we argue that disadvantage has a depressing effect through low external efficacy. This is in line with the representation argument of insider-outsider theory (Rueda, 2005). Case studies corroborate that workers suffering labour market disadvantage are poorly represented in the political arena (Palier and Thelen, 2010; Davidsson and Emmenegger, 2012; Hassel, 2014). From the perspective of a disadvantaged voter this means that political parties are (a) too similar to each other and (b) too far away from her preferred policy. In such a situation, turnout becomes less likely (Plane and Gershtenson, 2004; Adams et al., 2006). Because vote choice becomes meaningless, motivation to vote decreases.

Note that the external efficacy argument mashes up claims about individual motivation and party systems. Depending on the party system, the argument can be turned around. If there is a party that represents the interests of the disadvantaged, external efficacy and motivation to vote should increase. If some parties agitate against unresponsive political elites, which is a defining feature of populism, disadvantaged voters may be extra motivated to vote and to express their annoyance. Although we cannot test the party system argument in this article, it should be kept in mind given the populist turn European party systems have taken in recent years (Kriesi, 2014). ${ }^{1}$ What is important here is that disadvantaged voters are motivated not only by maximising economic benefits but also by the psychological gratification from 'punishing' mainstream parties. This leads us to the next step in our argument: vote choice.

\subsection{Labour market disadvantage and vote choice}

If the disadvantaged do vote (which we assume for a moment), political economy predicts a tendency towards left parties. The underlying reasoning is based on the spatial voting model and assumed proximity in demanded and supplied levels of redistribution (e.g. Cusack et al., 2006). We agree with the broad prediction, even if we remain agnostic with regards to assumptions of sophistication and economic self-interest maximisation. What we refer to as labour market disadvantage is a set of economic constraints and risks that are very tangible for affected individuals. Therefore, disadvantage increases the personal importance voters attach to socio-economic issues (Marx, 2015). Even if voters do not possess sophisticated knowledge of parties' exact position, most of them arguably have more than a rough idea where parties stand historically and currently on salient issues such as welfare and redistribution. Hence, we simply expect that disadvantaged voters have a strong personal interest in redistribution (which will be reflected in their vote choice) and some knowledge about which parties can be expected to cater it.

As mentioned already, supporting redistribution is not the only motivation for disadvantaged voters. They can also be motivated by the desire to express resentment with political elites and one way to do so is voting for populist or anti-system parties. This motive can be purely expressive, that is, voting against the system is psychologically rewarding in itself. It can also be instrumental, for instance, with the goal of incentivising more responsiveness of mainstream parties in the future (Kedar, 2005; Kselman and Niou, 2011). Whether expressively or

1 The comparative argument would bet that the disadvantaged are more likely to abstain in party systems in which there is a limited ideological choice. 


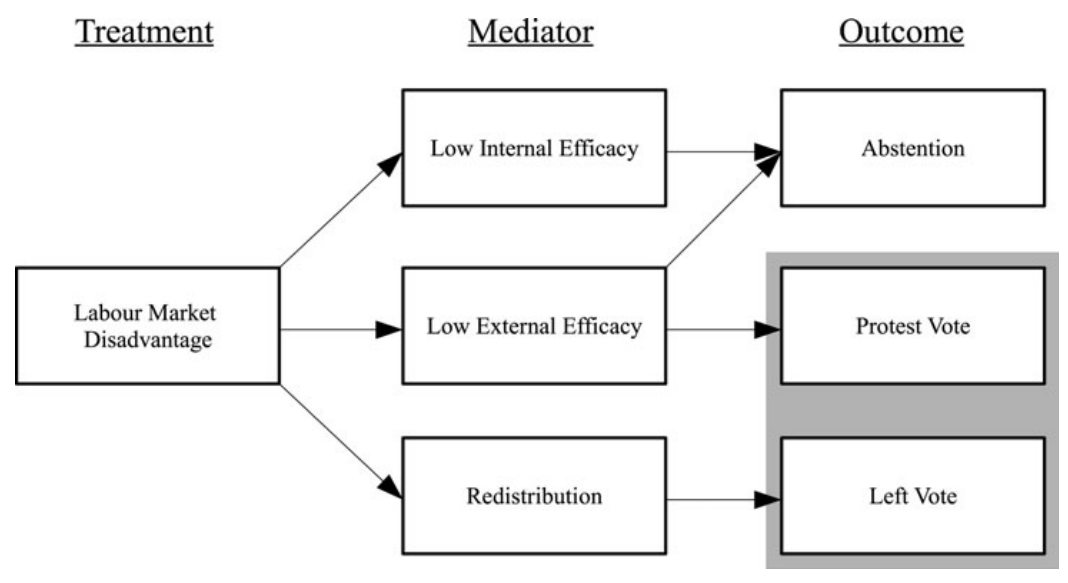

Figure 1 Overview on possible mediation relationships.

Notes: The grey box accounts for the possibility that protest vote and left vote overlap, such as in a vote for an extreme left party.

instrumentally motivated, the important point for us is that if labour market disadvantage leads to low external efficacy, as we argue based on the insider-outsider literature, protest parties become an alternative for disadvantaged voters.

\subsection{Bringing it all together}

In sum, we identify three mediators linking labour market disadvantage to political behaviour: internal efficacy, external efficacy and redistribution preferences (see Figure 1). If low internal efficacy dominates, we expect a higher propensity to abstain. In this case, disadvantaged (non-)voters become politically apathetic. If redistribution preferences dominate, we expect a higher propensity to vote left and no effect on abstention. The more complicated case is low external efficacy. Depending on the party system, it may lead to higher abstention (if there are no protest parties) or to protest voting (if there are such parties).

Low internal efficacy is a relatively distinct mechanism, because apathy probably does not even let clear policy preferences and normative assessments of parties develop. Low external efficacy and redistribution preferences, however, are likely to affect political behaviour simultaneously (this joint mediation is represented by the shaded area in Figure 1). ${ }^{2}$ As elaborated before, low external efficacy theoretically results from mainstream parties' unresponsiveness to disadvantaged voters' interests. What does that mean for vote choice? The straightforward answer is that in the (likely) case that disadvantage is jointly mediated by external efficacy and redistribution preferences, the disadvantaged will choose parties that combine a protest with a redistribution platform.

Voting for a mainstream left party, such as the Social Democrats, only allows supporting redistribution, not expressing protest. Voting radical right-wing parties only allows expressing

2 The mediators could exist simultaneously in the group of the disadvantaged, so that some disadvantaged suffer low efficacy whereas others primarily demand redistribution. They could also co-exist on the individual level and hence simultaneously affect individuals' decision making. We cannot empirically distinguish between these two possibilities because in both cases the two mediators jointly affect the average effect of labour market disadvantage on political behaviour. 
protest but typically not maximising redistributive social spending. In both cases low efficacy and redistribution preferences cancel each other out. However, they reinforce each other, for instance, in the case for radical left-wing parties, which combine an anti-establishment platform with maximum support for the welfare state. More generally, our framework implies that we should only expect unambiguous positive effects of labour market disadvantage on voting for parties which can mobilise potentially alienated voters and at the same time support redistributive policies (which could also be a radical right party adopting welfare chauvinism).

To sum up, our framework highlights three potential mediators linking labour market disadvantage to vote choice. The important message is that these causal chains should be modelled explicitly to avoid erroneous inferences. However, we do not see an a priori reason to prioritise any of the three channels. We are even agnostic as to whether a general theory is possible or helpful here; our hunch is that the question which mediator dominates strongly depends on individual and political context. ${ }^{3}$ We think that our framework will be most productive if it is translated into concrete hypotheses for the cases and research questions at hand. This is what we do in the following section for the Dutch case.

\section{The Dutch labour market and party system}

The Netherlands is a typical example of a dual labour market. Dismissal protection for workers with open-ended employment contracts is relatively strict (Eichhorst and Marx, 2012), which has contributed to an increased use of temporary contracts since the 1980s, a trend various governments have done little to counter (Emmenegger, 2014). In 2012, the Netherlands had the fourth largest share of temporary contracts in the EU-almost $20 \%$ of the dependent workforce (EUROSTAT, 2014). Part-time employment is very common in the Netherlands (with 50\% the highest incidence in the EU). However, with less than $10 \%$ (of all part-timers) in 2012, it had one of the lowest shares of involuntary part-time (EUROSTAT, 2014). This arguably reflects the beneficial treatment by the welfare state and high social acceptance of this type of work (Visser, 2002). Although the Netherlands has a statutory minimum wage, the incidence of low-wage employment as well as wage dispersion in the lower half of the earnings distribution is comparatively large. This reflects a continuous decline of the minimum wage relative to median earnings (Salverda and Mayhew, 2009). Whereas non-standard employment is relatively high, the Netherlands had a well below average unemployment rate throughout the 2000s and during the recent economic crisis. The unemployment rate in 2012 was $5.3 \%$ (EUROSTAT, 2014).

In a comparative perspective, the Dutch party system provides an interesting context to assess the voting behaviour of individuals with labour market disadvantages because it offers them a wide choice of different ideological positions. Since the general elections in 2012, 11 parties are represented in Parliament. Parties at the margins of the ideological spectrum performed relatively well. The right-wing populist Freedom Party (PVV) and the left-wing populist Socialist Party (SP) are the third and fourth strongest parties, respectively (see Figure 1). However, these parties have never been part of a governing coalition. We expect the presence of polarising parties to increase turnout amongst voters who are alienated

3 We have already pointed to the important role of the party system. It is beyond the scope of this article to discuss individual variation amongst the disadvantaged, although we see it as an important and logical next step in the debate. 


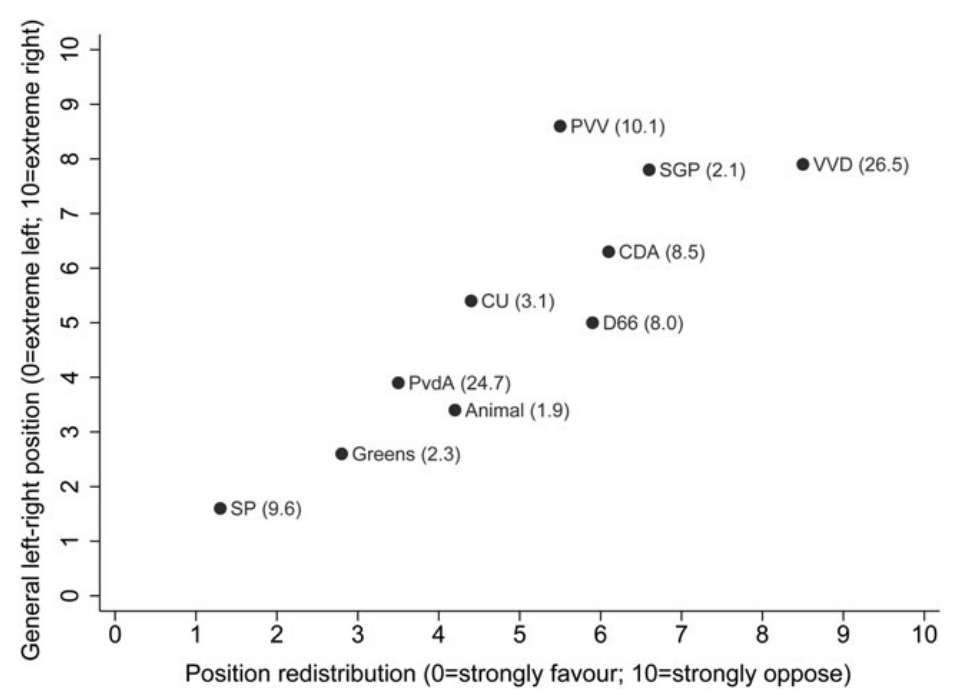

Figure 2 Left-right position and position on redistribution in the Dutch party system (2010).

Notes: No data available for the party 50+. Numbers in parentheses refer to seat share after 2012 election.

Source: Chapel Hill expert survey 2010 (Bakker et al., 2014).

from mainstream politics. In a comparative perspective, this stacks the cards against finding increased abstention amongst individuals with labour market disadvantages.

According to Lindvall and Rueda (2014), the behaviour of the major left party is crucial for the electoral choice of the disadvantaged. Under the leadership of Wim Kok in the 1990s, the Dutch Labour Party (PvdA) developed a rather centrist policy orientation. This is expressed in openness to coalitions with the Liberal Party (VVD) and measures of welfare state retrenchment (Green-Pedersen and van Kersbergen, 2002; Marx and Schumacher, 2013). We would therefore expect that the Labour Party is rather unpopular amongst individuals with labour market disadvantages.

Figure 2 plots the Dutch parties' general left-right position against their position on redistribution. ${ }^{4}$ Unsurprisingly, the two dimensions are closely aligned. A partial exception is the right-wing populist PVV, which given its extreme right position has a relatively moderate stance on redistribution. The fact that voting PVV allows expressing discontent with mainstream parties without supporting an anti-redistribution agenda could make the party attractive for individuals with labour market disadvantages.

In sum, translating our hypotheses into the context of the Dutch party system leads us to formulate the following four expectations. First, following the redistribution hypothesis, we

4 Figure 1 is based on data from the Chapel Hill expert survey released in 2010. The Chapel Hill expert survey locates parties of European countries on several important ideological and policy dimensions. Multiple academic experts are asked to locate their respective national parties on these dimensions. The parties' final score for each dimension is derived by averaging the single expert scores (see Bakker et al., 2014). 
expect a positive relationship between labour market disadvantage and electoral support for the Socialists, Labour and the Greens. Second, following the internal efficacy hypothesis, we expect labour market disadvantage to lead to increased abstention from voting. Third, following the external efficacy hypothesis, we expect labour market disadvantage to be positively associated with either increased support for the Socialists and the Freedom Party or abstention from voting. However, redistributive goals and the desire to cast a protest vote collide to a certain extent in the case of the Freedom Party, whereas they reinforce each other in the case of the Socialists. Hence, we expect that the Socialists are the only party that individuals with labour market disadvantages can endorse unambiguously if the twin effect of redistribution preferences and external efficacy is at work.

\section{Data and operationalisation}

For our empirical analysis, we make use of household panel data from the Dutch LISS (Longitudinal Internet Studies for the Social Sciences) database provided by CentERdata. This panel study started at the end of 2007 and consists of around 5000 Dutch households comprising 8000 individuals. Hence we are able to draw on five waves from 2008 to 2012. We focus only on the potential working population between the age of 18 and 65 years, and we exclude pensioners and students. The LISS data set is particularly suitable for our purpose because the core questionnaires include many useful items on employment status and political orientations. The internet-based survey format also delivers good response rates. Furthermore, the LISS includes a post-election survey conducted with the panel participants after the 2012 election, which we use to operationalise our dependent variable.

We exploit the data set's longitudinal information to create a more informative measure of labour market disadvantage, which is then used in a cross-sectional analysis of voting behaviour (2012 post-election survey). We dismiss the alternative of analysing within-case variation because our dependent variable, electoral behaviour, is not available on a yearly basis.

In addition, many variables in our analysis can be expected to be very resilient over time. The propensity to participate and underlying political orientations are often found to be rather stable and only affected by significant disruptive experiences (Plutzer, 2002; Prior, 2010). Hence, it is reasonable to assume that adverse labour market experiences need to accumulate over a long time period to lead to meaningful adjustments in individuals' beliefs about politics and associated behaviours. Our short five-year panel without yearly variation on the main variables is not a good fit for fixed-effects regressions. Yet we can use the longitudinal information to create a more valid measure of labour market disadvantage. The strength of our indicator, which we present below, is that it can distinguish between persistent and transient experiences of labour market disadvantage.

Our concept of labour market disadvantage builds on the four dimensions that are prominent in the comparative literature, particularly the insider-outsider and dualisation literature (Rueda, 2005; Emmenegger, 2009; Häusermann and Schwander, 2012; Marx and Picot, 2013): unemployment, involuntary part-time work, temporary employment and low-wage work. In the empirical analysis, we treat these four dimensions as comparable instances of labour market disadvantage because, as we have theoretically argued, every dimension results in a high degree of personal economic strain and because we expect people to repeatedly move between these different forms of disadvantage. This expectation is borne out by the data. For instance, in the five-year interval that we can observe with the LISS data, $36 \%$ of all 
respondents who have experienced temporary employment also experienced involuntary parttime work, $40 \%$ experienced low-wage work and $22 \%$ also experienced unemployment. In addition, we analysed these four dimensions separately. As the results provided in the Supplementary Material Appendix show, we observe the same relationships in the case of the four individual dimensions as we do in the case of the composite indicator.

Our composite indicator is based on four dichotomous sub-indicators. One of the four dimensions (temporary employment) is by definition dichotomous. Also unemployment and involuntary part-time employment are usually conceptualised and measured as discrete states. To allow for a straightforward aggregation, we also dichotomise the wage variable. Although this implies a certain loss of information, it is warranted by the non-linear nature of the effect we theorise. ${ }^{5}$

Our measure of unemployment is based on a monthly background measure of respondents' employment state. We code a person as having experienced unemployment if we observe at least four or more months of unemployment per year. Shorter unemployment spells (three months or less) are not considered because they might simply reflect frictional unemployment.

Our measure of involuntary part-time work captures workers who do not have a full-time job but would like to work more hours. Hence, we only consider workers who work part-time because they are not able to find a job with more hours. We code respondents as involuntary part-time workers if they work 36 hours or less and have a working hour aspiration that exceeds the actual working time by at least 5 hours to restrict our focus to workers who are clearly under-employed and therefore suffer from substantial socio-economic consequences.

Temporary employment is measured by a dummy coded 1 if respondents indicate that they are temporarily employed, on-call employed or a temp staffer.

Low-wage employment is measured on the basis of the hourly wages respondents earn. As information on hourly wages are not provided directly in the data, we calculate them from data on gross monthly income and weekly working hours. Therefore, this measure does not interfere with our definition of involuntary part-time work. The low-wage threshold is defined as two-thirds of the median hourly gross wage. This corresponds to the definition of the low-wage sector used by the OECD (2012). The median hourly wage in our data is $€ 16.17$. We therefore set the low-wage threshold to $€ 10.78$.

Our conceptualisation of labour market disadvantage takes into account these four different forms of disadvantage over time. Defining labour market disadvantage statically with

5 In principle, we could operationalise involuntary part-time employment (the difference between desired and actual working time), unemployment duration and wages continuously. However, in each case, the exact functional form is theoretically not known. Hence, the most straightforward way to operationalise involuntary part-time employment, unemployment and wages is to use a series of dummy variables to differentiate levels of under-employment, wage brackets and unemployment duration. However, since we are only interested in whether the respondents experienced substantial involuntary under-employment, low-wage work or prolonged unemployment, respectively, single dummy variables are sufficient. Moreover, having dichotomous indic ators on all four dimensions allows us to use a straightforward discounting procedure, explained later, to integrate information on negative labour market experiences from previous years in our cross-sectional model. Hence, whilst the dichotomisation implies a certain loss of information in the cross section, it allows for the consideration of information about previous labour market experiences. 
cross-sectional data can be problematic because it is likely that past experiences continue to have an effect. Accordingly, a labour market participant in $t_{1}$ with no previous experience of unemployment could behave very differently than another labour market participant in $t_{1}$ who was unemployed in $t_{0}$. Therefore, our approach is to use the longitudinal information to account for the labour market experiences respondents have had during the whole five-year period.

We use our four dimensions to create an index of labour market disadvantage that takes the value of 1 if at least one of the four disadvantages was experienced in a given year and 0 otherwise. We think it is reasonable to assume that the effects of labour market experiences do not immediately disappear from a person's mind on a yearly basis. At the same time, it is unlikely that past experiences have the same weight as contemporary ones. As time passes, memories of past labour market experiences fade from people's minds. Both effects can be taken into account by using a discounting procedure. We carry over experiences from one year into the next but use a discounting factor to model the fading relevance of previous experiences.

We implement this idea with the following simple operation:

$$
\text { Disadvantage }_{\text {discounted }}=X_{t}+X_{t-1} \delta+X_{t-2} \delta^{2} \cdots+X_{t-n} \delta^{n}
$$

where $X$ is a dummy variable measuring labour market disadvantage for a person in each year and $\delta$ is the discounting factor (see the Supplementary Material Appendix for an illustrative example of the discounting procedure). We use a discounting factor of 0.7 , which allows an experience to lose $50 \%$ of its relevance in two years but remain substantial for a considerable time period. However, the empirical results presented in the subsequent analysis are robust to changes of the discounting factor to 0.8 (relevance reduced by $36 \%$ over two years) and 0.6 (relevance reduced by $64 \%$ over two years). Figure 3 displays the values of our discounted disadvantage index.

With regards to the other variables of interest, we capture preferences for redistribution using a survey item measuring respondents' opinion on whether income differences should decrease or increase. The variable ranges from 'differences should increase' (1) to 'differences should decrease' (5). Admittedly, this variable is not optimal because it does not involve any discussion of the role of government in shaping income differences. However, for reasons of data availability, we have to work with this operationalisation.

To measure external efficacy we rely on respondents' confidence in and satisfaction with political institutions. These measures are good approximations of individuals' attitudes towards elite responsiveness and the general functioning of the political system. Previous research has shown that these indicators strongly correlate with various measures of political trust and external efficacy (Craig et al., 1990). We use the LISS data's measures of confidence in and satisfaction with political actors to conduct a confirmatory factor analysis (CFA) helping us construct a measure of external efficacy. We predict a latent variable with measures on confidence in and satisfaction with political parties, politicians and the parliament (based on six Likert scales ranging from 0 to 10). After accounting for the covariance between the items, we receive a very good model fit confirming that the six items capture a single latent construct. $^{6}$

6 The chi-square test is insignificant indicating a nearly perfect fit. We receive an RMSEA clearly below 0.05. The SRMR is far below 0.08 . See Table A2 in the Supplementary Material Appendix for a complete report of the results of the CFA. 


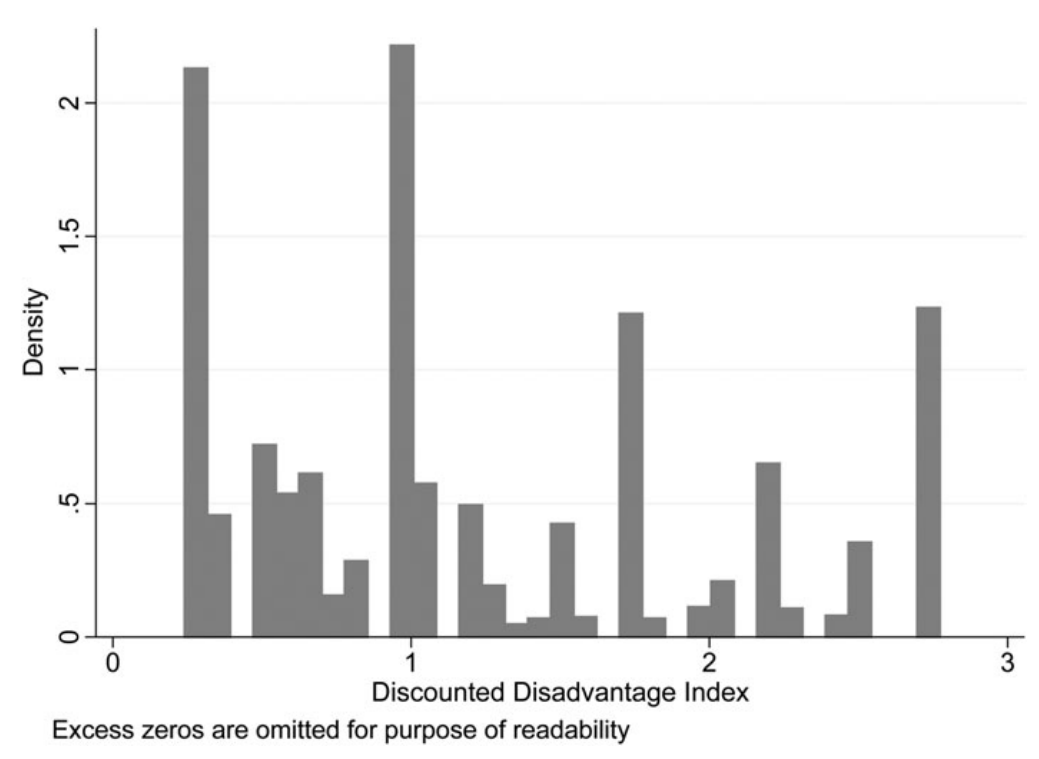

Figure 3 Histogram of discounted disadvantage index $(\delta=0.7)$. Notes: Own calculations based on LISS data set.

The post-election survey includes three survey items tapping respondents' internal efficacy. On a four-point Likert scale ranging from 'fully agree' to 'fully disagree,' respondents were asked to rate the statements: (1) 'I feel well qualified to play an active role in politics;' (2) 'I have a good understanding of the most important political problems in our country;' (3) 'Sometimes politics seems so complicated that people like me cannot really understand it.' CFA of the three items produces a good model fit, confirming that they capture a common latent construct. ${ }^{7}$

Turning to our dependent variables, we are interested in three types of voting behaviour. First, we hypothesise that disadvantage is mediated by external efficacy and leads to an increased likelihood of protest voting. Hence, we create a dummy variable called 'protest' which is 1 if a respondent voted SP, PVV or abstained in the 2012 parliamentary elections. Second, we hypothesise that disadvantage is mediated by internal efficacy and reduces the likelihood to turnout. This is measured by a dummy indicating 1 if a respondent abstained from the election. Third, we hypothesise that disadvantage is mediated by respondents' preferences for redistribution, leading to an increased probability to vote for pro-redistribution parties. Accordingly, we create a dummy measuring if a respondent voted PvdA, SP or Greens. As a robustness check we also break up these dummies and analyse the effect of labour market disadvantage on voting for single parties.

7 The chi-square test is insignificant, indicating a nearly perfect fit. We receive an RMSEA clearly below 0.05. The SRMR is far below 0.08 . See Table A3 in the Supplementary Materials Appendix for a complete report of the results of the CFA. 
We control for gender, age and education. Moreover, we include a dummy for respondents who willingly do not participate in the labour market (non-participants). ${ }^{8}$ Hence, our reference group in the subsequent analysis are individuals who have not experienced any disadvantages and did not indicate any reasons they do not participate in the labour market. Further control variables are union membership and household income. Union members are expected to favour redistribution and be more likely to vote for left parties. Moreover, since union membership is a form of social participation, union members may have higher levels of internal and external efficacy. Resource endowment is another important determinant of political behaviour. To control for household effects we include dummy variables indicating the position of a respondent in the household. We rely on information on whether the respondent indicates being the main contributor to the household income. Our dummy variable captures respondents who provide the main income and have someone who relies on them (a spouse and/or children). The main carer dummy variable captures respondents who indicated that they are wedded to someone who provides the main income.

The following empirical part uses a mediation analysis to investigate through which paths labour market disadvantage affects vote choice. The central goal of such a mediation analysis is the identification of causal mechanisms proposed by theoretical arguments (Imai et al., 2010,2011). On a basic level, mediation analysis tells us whether part of an independent variable's effect (treatment variable) on the dependent variable is translated via another variable (mediator variable). Hence, we are interested in the part of the variance the treatment variable (labour market disadvantage) explains of the mediator variable (external efficacy, internal efficacy and redistribution preferences) and how much of that part is translated into a significant effect of the mediator variable on voting behaviour.

\section{Analysis}

We begin our analysis by investigating the direct effect of the three mediator variables on vote choice. We estimate a multinomial logit regression with our mediators as predictors (see Table A4 in the Supplementary Material Appendix). As expected, strong preferences for redistribution significantly increase the probability to vote for PvdA, SP or Greens, whilst the effect on the VVD is significant and negative. High external efficacy significantly decreases the likelihood of voting for left or protest parties (PvdA, PVV and SP). Moreover, high external efficacy decreases the probability of abstaining from the election. Also high internal efficacy significantly decreases the probability of abstention. These findings confirm that our mediator variables have the expected effects.

In a next step we investigate the direct effect of our disadvantage indicator on vote choice. Table 1 presents two multinomial logit regressions with the party D66 as base outcome (D66 is the most centrist party according to the Chapel Hill left-right measure). Panel A of Table 1 shows that experiencing labour market disadvantage significantly increases the probability of voting SP. Several mechanisms could explain this finding. Disadvantage could work through economic self-interest and increase the preferences for redistribution, which leads to a vote for the pro-redistribution party SP. Alternatively, disadvantage could decrease respondents' external efficacy and lead to an SP vote in form of a protest vote. Indeed, the fact that we observe a

8 These are respondents who indicated that they have a reason to not participate in the labour market, such as childcare, disabilities and health issues. 
Table 1 Multinomial estimates of vote choice

\begin{tabular}{|c|c|c|c|c|c|c|c|c|c|}
\hline & (1) & (2) & (3) & (4) & (5) & (6) & (7) & (8) & (9) \\
\hline & Abstention & VVD & PvdA & PVV & SP & CDA & D66 & ChristenUn & Greens \\
\hline \multicolumn{10}{|l|}{ Panel A } \\
\hline Disadvantage index & $\begin{array}{l}0.139 \\
(0.107)\end{array}$ & $\begin{array}{l}0.00307 \\
(0.0991)\end{array}$ & $\begin{array}{l}0.0890 \\
(0.100)\end{array}$ & $\begin{array}{l}0.113 \\
(0.122)\end{array}$ & $\begin{array}{l}0.237 * * \\
(0.109)\end{array}$ & $\begin{array}{l}0.0503 \\
(0.131)\end{array}$ & Base outcome & $\begin{array}{l}-0.0492 \\
(0.172)\end{array}$ & $\begin{array}{l}0.108 \\
(0.163)\end{array}$ \\
\hline Constant & $\begin{array}{l}6.048 * * \\
(0.589)\end{array}$ & $\begin{array}{l}3.265 * * \\
(0.526)\end{array}$ & $\begin{array}{l}1.988 * * * \\
(0.557)\end{array}$ & $\begin{array}{l}4.921 * * * \\
(0.687)\end{array}$ & $\begin{array}{l}2.914 * * * \\
(0.624)\end{array}$ & $\begin{array}{l}-0.249 \\
(0.711)\end{array}$ & & $\begin{array}{l}1.731 * * \\
(0.805)\end{array}$ & $\begin{array}{l}-1.795 * \\
(0.842)\end{array}$ \\
\hline Observations & 2827 & 2827 & 2827 & 2827 & 2827 & 2827 & 2827 & 2827 & 2827 \\
\hline \multicolumn{10}{|l|}{ Panel B } \\
\hline Disadvantage index & $\begin{array}{l}0.0415 \\
(0.134)\end{array}$ & $\begin{array}{l}0.000242 \\
(0.119)\end{array}$ & $\begin{array}{l}0.0499 \\
(0.118)\end{array}$ & $\begin{array}{l}0.0154 \\
(0.144)\end{array}$ & $\begin{array}{l}0.192 \\
(0.127)\end{array}$ & $\begin{array}{l}0.0307 \\
(0.148)\end{array}$ & Base outcome & $\begin{array}{l}-0.0685 \\
(0.202)\end{array}$ & $\begin{array}{l}0.189 \\
(0.173)\end{array}$ \\
\hline Redistribution & $\begin{array}{l}0.00434 \\
(0.123)\end{array}$ & $\begin{array}{l}-0.640 * * * \\
(0.102)\end{array}$ & $\begin{array}{l}0.490 * * * \\
(0.105)\end{array}$ & $\begin{array}{l}-0.0600 \\
(0.140)\end{array}$ & $\begin{array}{l}0.534 * * * \\
(0.124)\end{array}$ & $\begin{array}{l}-0.0535 \\
(0.134)\end{array}$ & & $\begin{array}{l}-0.0507 \\
(0.157)\end{array}$ & $\begin{array}{l}0.848 * * * \\
(0.187)\end{array}$ \\
\hline External efficacy & $\begin{array}{l}-0.748 * * * \\
(0.129)\end{array}$ & $\begin{array}{l}0.0224 \\
(0.126)\end{array}$ & $\begin{array}{l}-0.257^{* *} \\
(0.121)\end{array}$ & $\begin{array}{l}-0.921 * * * \\
(0.137)\end{array}$ & $\begin{array}{l}-0.534 * * * \\
(0.127)\end{array}$ & $\begin{array}{l}0.260 \\
(0.177)\end{array}$ & & $\begin{array}{l}-0.102 \\
(0.196)\end{array}$ & $\begin{array}{l}-0.00822 \\
(0.175)\end{array}$ \\
\hline Internal efficacy & $\begin{array}{l}-0.588 * * * \\
(0.165)\end{array}$ & $\begin{array}{l}-0.149 \\
(0.147)\end{array}$ & $\begin{array}{l}0.0451 \\
(0.143)\end{array}$ & $\begin{array}{l}0.0244 \\
(0.176)\end{array}$ & $\begin{array}{l}-0.113 \\
(0.160)\end{array}$ & $\begin{array}{l}-0.276 \\
(0.201)\end{array}$ & & $\begin{array}{l}0.0399 \\
(0.242)\end{array}$ & $\begin{array}{l}0.248 \\
(0.213)\end{array}$ \\
\hline Constant & $\begin{array}{l}4.538 * * * \\
(0.841)\end{array}$ & $\begin{array}{l}5.390 * * * \\
(0.685)\end{array}$ & $\begin{array}{l}-0.126 \\
(0.758)\end{array}$ & $\begin{array}{l}4.749 * * * \\
(0.996)\end{array}$ & $\begin{array}{l}0.285 \\
(0.895)\end{array}$ & $\begin{array}{l}-0.825 \\
(0.941)\end{array}$ & & $\begin{array}{l}2.649 * * * \\
(0.994)\end{array}$ & $\begin{array}{l}-5.701 * \% \\
(1.333)\end{array}$ \\
\hline Observations & 2147 & 2147 & 2147 & 2147 & 2147 & 2147 & 2147 & 2147 & 2147 \\
\hline
\end{tabular}

Notes: Robust standard errors in parentheses. ${ }^{* *} P<0.01,{ }^{*} P<0.05,{ }^{*} P<0.1$. SGP, Animal, 50 plus omitted for purpose of readability. Complete set of control variables included. 
direct effect of disadvantage only for the SP could be due to the hypothesised simultaneous existence of the two mechanisms. In a similar vein, the non-findings for the other categories, such as abstention, could be the result of mediation effects cancelling each other out. Panel B of Table 1 further demonstrates the importance of mediation effects. Adding the three mediator variables to the model causes the effect of disadvantage on voting SP to turn insignificant.

Next we conduct a mediation analysis with the goal of investigating the indirect effect of labour market disadvantage on vote choice. Recent developments in mediation analysis provide us with an easy-to-implement strategy to estimate mediation effects for binary outcome models. ${ }^{9}$ We employ the method proposed by Imai et al. (2010) because its simulation-based algorithm accommodates a broad range of statistical frameworks and provides average mediation effects with confidence intervals. Its logic is based on an experimental framework, but the method can just as well be used for observational data (Imai et al., 2011).

The mediation effect we are interested in results from the differences in the outcome if we estimate our dependent variable with the mediator (1) under the condition of having estimated our mediator with the independent variable of interest and (2) under the condition of omitting our independent variable of interest from the estimation of the mediator (Imai et al., 2010, p. 311). The estimation of this difference in outcome is the average (indirect) treatment effect we are interested in. This estimation strategy fits two separate models: one for the mediator variable and one for the observed outcome. First, we estimate the mediator variable with our treatment variable (the labour market disadvantage index) plus controls. Subsequently, we estimate the outcome with our mediator, the treatment and controls. From the two models, the model parameters are simulated from their sampling distribution. Based on the simulated potential values of the mediator and the resulting simulated outcome values, we can estimate the average direct and indirect effects of the main independent (treatment) variable (Hicks and Tingley, 2011).

Table 2 presents the regressions the mediation analysis is based on. Models 5 to 7 use ordinary least squares (OLS) to estimate the effect of labour market disadvantage on the three mediators (first step of the mediation analysis). We see that labour market disadvantage significantly reduces external efficacy and increases preferences for redistribution. Yet the coefficient for internal efficacy is only significant at the $10 \%$ level and points into the wrong direction. Therefore, labour market disadvantage does not seem to affect respondents' level of internal efficacy.

Models 1 to 4 estimate types of voting behaviour using probit regressions, including the three mediator variables (second step of the mediation analysis). Labour market disadvantage does not seem to have a direct effect on any of the outcome variables. Yet we see that external efficacy negatively affects protest voting and abstention, but has no significant effect on redistribution voting. Redistribution has a significant positive impact on redistribution voting and protest voting but not on abstention. Internal efficacy significantly affects all four outcomes. Whilst there is a negative effect on protest voting and abstention, internal efficacy seems to increase the probability of a redistribution vote. Hence, the mediator variables affect the voting dummies as expected, although there are a series of effects that we did not anticipate. Yet the central question is whether some of the effects of disadvantage on the mediators are translated into voting behaviour.

9 Conducting a simple Sobel test with a non-linear multinomial logit model is not possible. Solutions for non-linear models only allow for binary dependent variables (Hayes and Preacher, 2010). 
Table 2 Mediation analysis

\begin{tabular}{|c|c|c|c|c|c|c|c|}
\hline & \multicolumn{4}{|l|}{ Probit } & \multicolumn{3}{|l|}{ OLS } \\
\hline & $(1)$ & (2) & (3) & (4) & $(5)$ & (6) & (7) \\
\hline & Protest vote & Protest vote (without SP) & Redistribution vote & Abstention & External efficacy & Redistribution & Internal efficacy \\
\hline \multirow[t]{2}{*}{ Disadvantage index } & 0.0513 & 0.011 & 0.0323 & 0.0024 & $-0.1552 * * *$ & $0.1134 * * *$ & $0.0267^{*}$ \\
\hline & $(0.0332)$ & $(0.0369)$ & $(0.0317)$ & $(0.0423)$ & $(0.0406)$ & $(0.0211)$ & $(0.016)$ \\
\hline \multirow[t]{2}{*}{ External efficacy } & $-0.1678 * * *$ & $-0.1529 * * *$ & -0.0135 & $-0.1047 * * *$ & & & \\
\hline & $(0.0172)$ & $(0.0186)$ & $(0.0166)$ & $(0.0208)$ & & & \\
\hline \multirow[t]{2}{*}{ Redistribution } & $0.1064 * * *$ & -0.0316 & $0.3628 * * *$ & -0.0063 & & & \\
\hline & $(0.0317)$ & $(0.0354)$ & $(0.0316)$ & $(0.0406)$ & & & \\
\hline \multirow[t]{2}{*}{ Internal efficacy } & $-0.1665 * * *$ & $-0.2128 * * *$ & $0.0912 * * *$ & $-0.3348 * * *$ & & & \\
\hline & $(0.0415)$ & $(0.0462)$ & $(0.0393)$ & $(0.0536)$ & & & \\
\hline \multirow[t]{2}{*}{ Gender } & -0.115 & $-0.2081 * *$ & 0.0651 & -0.1296 & -0.0149 & $0.1194 * * *$ & $-0.3187 * * *$ \\
\hline & $(0.0717)$ & $(0.0809)$ & $(0.0693)$ & $(0.0924)$ & $(0.0834)$ & $(0.0455)$ & $(0.0334)$ \\
\hline \multirow[t]{2}{*}{ Age } & $-0.0983 * *$ & $-0.1441 * *$ & $0.1222 * * *$ & $-0.1379 * * *$ & -0.0361 & $0.0725 * *$ & $0.0905 * *$ \\
\hline & $(0.0272)$ & $(0.0299)$ & $(0.0265)$ & $(0.0338)$ & $(0.0298)$ & $(0.0172)$ & $(0.0131)$ \\
\hline \multirow[t]{2}{*}{ Education } & $-0.0272 * * *$ & $-0.0440 * * *$ & $0.0257 * * *$ & $-0.0283 * * *$ & $0.0438 * *$ & $-0.0131 * *$ & $0.0324 * * *$ \\
\hline & $(0.0054)$ & $(0.0062)$ & $(0.0052)$ & $(0.0069)$ & $(0.0060)$ & $(0.0034)$ & $(0.0025)$ \\
\hline \multirow[t]{2}{*}{ Non-participants } & 0.0081 & -0.0801 & $0.1239^{*}$ & -0.0709 & 0.0119 & 0.0771 & 0.0067 \\
\hline & $(0.0746)$ & $(0.0852)$ & $(0.0721)$ & $(0.0954)$ & $(0.0900)$ & $(0.0496)$ & $(0.0355)$ \\
\hline \multirow[t]{2}{*}{ Union member } & $0.1265^{*}$ & -0.0422 & $0.3133^{* * *}$ & -0.0507 & $-0.1523 *$ & $0.3066 * *$ & -0.0019 \\
\hline & $(0.0722)$ & $(0.0831)$ & $(0.0675)$ & $(0.0948)$ & $(0.0849)$ & $(0.0434)$ & $(0.0347)$ \\
\hline \multirow[t]{2}{*}{ Migrant background } & -0.0302 & -0.1276 & $0.1530 * *$ & 0.1094 & $-0.1903 *$ & -0.0442 & -0.0677 \\
\hline & $(0.0862)$ & $(0.0995)$ & $(0.0817)$ & $(0.1092)$ & $(0.1046)$ & $(0.0602)$ & $(0.0427)$ \\
\hline \multirow[t]{2}{*}{$\mathrm{HH}$ income } & $-0.081 * * *$ & $-0.052^{* * *}$ & $-0.047 * * *$ & $0.400 *$ & $0.098 * * *$ & $-0.073 * * *$ & $0.037 * * *$ \\
\hline & $(0.016)$ & $(0.018)$ & $(0.013)$ & $(0.221)$ & $(0.017)$ & $(0.010)$ & $(0.006)$ \\
\hline
\end{tabular}


Table 2 Continued

\begin{tabular}{|c|c|c|c|c|c|c|c|}
\hline & \multicolumn{4}{|l|}{ Probit } & \multicolumn{3}{|l|}{ OLS } \\
\hline & (1) & (2) & (3) & (4) & (5) & (6) & (7) \\
\hline & Protest vote & Protest vote (without SP) & Redistribution vote & Abstention & External efficacy & Redistribution & Internal efficacy \\
\hline \multirow[t]{2}{*}{ Main income earner } & $0.1387^{*}$ & $0.1682^{*}$ & $-0.0421^{*}$ & 0.0864 & $-0.1558^{*}$ & -0.0516 & $-0.0752 * *$ \\
\hline & $(0.0759)$ & $(0.0864)$ & $(0.0717)$ & $(0.0965)$ & $(0.0899)$ & $(0.0488)$ & $(0.0356)$ \\
\hline \multirow[t]{2}{*}{ Main carer } & 0.1163 & $0.1689^{*}$ & $-0.026^{*}$ & 0.0105 & -0.0150 & -0.0540 & $-0.1906 * * *$ \\
\hline & $(0.080)$ & $(0.0901)$ & $(0.0772)$ & $(0.103)$ & $(0.0935)$ & $(0.0512)$ & $(0.0392)$ \\
\hline \multirow[t]{2}{*}{ Constant } & 0.1144 & 0.7184 & -2.8028 & 0.0642 & $-0.667 * \cdots$ & $3.8645 * * *$ & -0.8211 \\
\hline & $(0.2193)$ & $(0.2420)$ & $(0.2193)$ & $(0.2721)$ & $(0.199)$ & $(0.1157)$ & $(0.0849)$ \\
\hline$R^{2}$ & & & & & 0.07 & 0.10 & 0.17 \\
\hline Pseudo $R^{2}$ & 0.11 & 0.11 & 0.09 & 0.09 & & & \\
\hline Observations & 2557 & 2557 & 2557 & 2557 & 2557 & 2557 & 2557 \\
\hline
\end{tabular}

Notes: Robust standard errors in parentheses. ${ }^{* *} P<0.01,{ }^{* *} P<0.05,{ }^{*} P<0.1$. HH income multiplied by 1000. 
Table 3 Simulated direct and indirect effects of labour market disadvantage on protest voting

\begin{tabular}{llcc}
\hline Effect & Mean & \multicolumn{2}{l}{$95 \%$ confidence interval } \\
\hline Via external efficacy & & & \\
$\quad$ Average mediation & $0.008^{* *}$ & -0.004 & 0.012 \\
$\quad$ Average direct effect & 0.015 & & 0.035 \\
Via redistribution & & 0.001 & 0.006 \\
$\quad$ Average mediation & $0.003^{* *}$ & -0.003 & 0.035 \\
Average direct effect & 0.015 & -0.003 & 0.0002 \\
Via internal efficacy & & -0.003 & 0.035 \\
Average mediation & -0.001 & & \\
Average direct effect & 0.015 & & \\
\hline
\end{tabular}

Notes: ${ }^{*} P<0.05, * P<0.10$.

Table 3 presents the average mediation (indirect effect) and the average direct effect of labour market disadvantage on protest voting. We can see that there is a significant indirect effect of disadvantage on protest voting via external efficacy and redistribution, but no effect for internal efficacy. The coefficient for external efficacy is the biggest and the reported percentage of the effect being mediated is $32 \%$ for external efficacy and only $18 \%$ for redistribution, which shows that the dominant mediator for protest voting is external efficacy. Experiencing labour market disadvantages seems to reduce external efficacy, which in turn leads to an increased probability of voting for extreme parties or abstain from the election.

The significant indirect effect on protest voting through redistribution in Table 3 could be due to the SP votes, which are also included in the protest vote dummy. To test for this possibility Model 2 in Table 2 excludes SP votes from the dependent variable (protest voting). Table 4 presents the resulting mediation effects and confirms that the indirect effect via redistribution is solely the result of the SP votes being included in the outcome of Model 1. Excluding SP votes results in the average mediation via redistribution turning insignificant. Put differently, whilst low external efficacy significantly increases the probability of a protest vote or abstention, redistribution preferences only affect the likelihood of voting for the SP.

According to our hypotheses, redistribution preferences should also mediate the effect of disadvantage on other pro-redistribution parties such as the PvdA and the Greens. Table 5 presents the results of the mediation analysis based on Model 3 from Table 2. In line with our expectations, labour market disadvantage has a significant indirect effect on redistribution voting through respondents' preferences for redistribution. Put differently, negative labour market experiences tend to increase preferences for redistribution, which in turn result in a higher probability to vote for pro-redistribution parties such as the PvdA, the SP and the Greens.

Finally, we have hypothesised internal efficacy to mediate the negative effect of labour market disadvantage on abstention. However, as mentioned, labour market disadvantage does not have the expected effect on internal efficacy (see Model 7 in Table 2). Hence, internal efficacy should not have any observable mediation effect. Table 6 displays the results of our mediation analysis for the outcome abstention. It shows that the effect of disadvantage on abstention is exclusively mediated by external efficacy. 
Table 4 Simulated direct and indirect effects of labour market disadvantage on protest voting (without SP vote)

\begin{tabular}{lccr}
\hline Effect & Mean & $95 \%$ confidence interval & \\
\hline Via external efficacy & & & \\
Average mediation & $0.005^{* * *}$ & 0.002 & 0.008 \\
Average direct effect & 0.002 & -0.013 & 0.019 \\
Via redistribution & & & 0.001 \\
Average mediation & -0.001 & -0.003 & 0.019 \\
Average direct effect & 0.002 & -0.013 & \\
\hline
\end{tabular}

Notes: $* * P<0.05,{ }^{*} P<0.10$.

Table 5 Simulated direct and indirect effects of labour market disadvantage on redistribution vote

\begin{tabular}{lllr}
\hline Effect & Mean & $95 \%$ confidence interval & \\
\hline Via external efficacy & & & \\
$\quad$ Average mediation & 0.001 & -0.001 & 0.002 \\
$\quad$ Average direct Effect & 0.011 & -0.009 & 0.031 \\
Via redistribution & & & 0.019 \\
$\quad$ Average mediation & $0.013^{* *}$ & 0.008 & 0.031 \\
Average direct effect & 0.011 & -0.009 & \\
\hline
\end{tabular}

Notes: $* P<0.05, * P<0.10$.

In sum, the mediation analysis reveals two important findings. First, labour market disadvantage increases the probability of voting for radical parties or to abstain from the election. This relationship is mediated by the respondents' level of external efficacy. Second, labour market disadvantage increases the probability of voting for pro-redistribution parties. This effect is mediated by the respondents' preferences for redistribution. In contrast, labour market disadvantage has no effect on internal efficacy. Thus, even though being a strong predictor of voting behaviour in general, internal efficacy does not mediate the effect of labour market disadvantage on political behaviour.

Regarding the robustness of these findings, readers might be concerned about the fact that we have combined votes for different parties into dummies. Therefore, we have conducted mediation analyses for single party votes. As the mediation analysis for voting for individual parties shows (see Tables A5-A10 in the Supplementary Material Appendix), our findings hold: the effect of disadvantage on abstention and voting for the PVV is exclusively mediated by external efficacy. Voting PvdA is exclusively mediated by preferences for redistribution. Both mediators influence the propensity to vote for the SP. In contrast, we find that the mediation effects cancel each other out in the case of the Greens. Here, disadvantage exerts a positive effect via redistribution, whilst simultaneously impacting negatively via external efficacy. ${ }^{10}$

10 In the Supplementary Material Appendix we also provide a sensitivity test of the mediation relation proposed by Imai et al. (2010). 
Table 6 Simulated direct and indirect effects of labour market disadvantage on vote abstention

\begin{tabular}{llcl}
\hline Effect & Mean & \multicolumn{2}{l}{$95 \%$ confidence interval } \\
\hline Via external efficacy & & & \\
$\quad$ Average mediation & $0.003^{* *}$ & 0.001 & 0.005 \\
Average direct effect & 0.0005 & -0.014 & 0.015 \\
Via internal efficacy & & & \\
Average mediation & -0.002 & -0.004 & 0.0002 \\
Average direct effect & 0.0005 & -0.014 & 0.015 \\
\hline
\end{tabular}

Notes: ${ }^{*} P<0.05,{ }^{*} P<0.10$.

Moreover, as we have highlighted, our results are robust if we disaggregate our combined disadvantage measure into the four single dimensions (unemployment, low-wage work, involuntary part-time and temporary work). Tables A11 to A17 in the Supplementary Material Appendix show that the significant effects on protest vote via external efficacy and on redistribution vote via redistribution preferences hold for all four sub-dimensions.

\section{Conclusion}

With this article we advance the literature linking labour market experiences and political behaviour. Whilst they have often been analysed separately, we argue and show that psychological and instrumental mechanisms coexist. Accordingly, we have found empirical evidence that labour market experiences are mediated by both preferences for redistribution as well as external efficacy. This supports our initial presumption that these separate research strands on the labour market's effects on political behaviour can and should be combined. The co-existing mechanisms can amplify a relationship, such as their joint effect on the propensity to vote SP, but they can also cancel each other out, as in the case of the Greens.

We did not find an effect of disadvantage on internal efficacy and therefore also no mediated effect on political behaviour. This is an interesting finding in its own right. It suggests that labour market disadvantage is mediated by adverse feelings about the political system, not by subjective political competence. A possible reason underlying the non-finding is that a sense of internal efficacy becomes resilient to change once basic political socialisation is complete. This would diminish the effect of disadvantage later in life. Future research should assess the role of labour market experiences at different life cycle stages. The positive finding for external efficacy corroborates insider-outsider and dualisation arguments, which suggest that political behaviour is not the automatic outcome of labour market disadvantage. We support the view that behaviour of political elites and representation of interests of disadvantaged workers matter.

This links to the question of whether our results are generalisable. This article's intention was to advance a general framework for studying political behaviour of disadvantaged workers. We are confident that it will serve as a useful heuristic device to develop hypotheses about political effects of labour market experiences in very different contexts. But we are well aware that our empirical findings are context-dependent to some extent. Whilst we expect similar effects in many other advanced industrial democracies, this would have to be demonstrated empirically. 
Three factors are likely to matter in a comparative perspective: party systems, party behaviour as well as welfare state and labour market context. For instance, disadvantage and low external efficacy did not foster abstention in the Netherlands, but they might do so in a twoparty system where no party voices anger about the establishment. As the findings by Lindvall and Rueda (2014) indicate, strategies of major left parties can influence whether voters feel alienated from mainstream parties. In some countries, it could be that welfare chauvinistic right-wing parties benefit from redistribution demand and low external efficacy of disadvantaged workers. Finally, it might be that we have under-estimated the effect of disadvantage on internal efficacy, because we have chosen a country with sound labour market performance and generous unemployment benefits.

These limitations notwithstanding, our results carry important messages for the discussed debates. We show that the political behaviour literature would be well advised to pay more attention to different forms of labour market disadvantage as well as to the mediating role of external efficacy (as opposed to the currently dominant perspectives on resources and civic skills). Political economists should make greater efforts to go beyond structuralist reasoning when theorising effects on political behaviour and specifically include the possibility of political alienation in their models.

We regard this research as preliminary evidence on the potential role of psychological and instrumental mechanisms. Further research will be needed to investigate the functioning of the different mechanisms and their interplay. This will require comparative evidence, but it will also require opening up the black boxes with regard to the underlying causal models.

\section{Acknowledgements}

Earlier versions of this paper were presented at the Council for European Studies Annual Conference 2014 and the Political Research Seminar at the University of Zurich. We thank all participants and in particular Christopher Buß, Fabrizio Gilardi, Jane Gingrich, Silja Häusermann, Johannes Lindvall, David Rueda and the three anonymous reviewers for the helpful suggestions and comments. Paul Marx's research was supported by a grant from the Carlsberg Foundation [2012_01_0494].

\section{Supplementary material}

Supplementary material is available at SOCECO online.

\section{References}

Acock, A., Clarke, H. D. and Stewart, M. C. (1985) 'A New Model for Old Measures-A Covariance Structure-Analysis of Political Efficacy’, Journal of Politics, 47, 1062-1084.

Adams, J., Dow, J. and Merrill, S. (2006) 'The Political Consequences of Alienation-based and Indifference-based Voter Abstention: Applications to Presidential Elections', Political Behavior, 28, 65-86.

Adman, P. (2008) 'Does Workplace Experience Enhance Political Participation? A Critical Test of a Venerable Hypothesis', Political Behavior, 30, 115-138.

Bakker, R., de Vries, C., Edwards, E., Hooghe, L., Jolly, S., Marks, G., Polk, J., Rovny, J., Steenbergen, M. and Vachudova, M. A. (2014) 'Measuring Party Positions in Europe: The Chapel Hill Expert Survey Trend File, 1999-2010', Party Politics, 21, 143-152. 
Balch, G. A. (1974) 'Multiple Indicators in Survey Research: The Concept "Sense of Efficacy”, Political Methodology, 1, 1-43.

Bechtel, M., Hainmueller, J. and Margalit, Y. (2014) 'Preferences for International Redistribution: The Divide over the Eurozone Bailouts', American Journal of Political Science, 58, 835-856.

Benach, J., Vives, A., Amable, M., Vanroelen, C., Tarafa, G. and Muntaner, C. (2014) 'Precarious Employment: Understanding an Emerging Social Determinant of Health', Annual Review of Public Health, 35, 229-253.

Craig, S. C., Niemi, R. G. and Silver, G. E. (1990) 'Political Efficacy and Trust: A Report on the NES Pilot Study', Political Behavior, 12, 289-314.

Cusack, T., Iversen, T. and Rehm, P. (2006) 'Risks at Work: The Demand and Supply Sides of Government Redistribution', Oxford Review of Economic Policy, 22, 365-389.

Davidsson, J. B. and Emmenegger, P. (2012) 'Insider-Outsider Dynamics and the Reform of Job Security Legislation'. In Bonoli, G. and Natali, D. (eds) The Politics of the New Welfare State, Oxford, Oxford University Press, pp. 206-232.

Eichhorst, W. and Marx, P. (2012) 'Whatever Works: Dualisation and the Service Economy in Bismarckian Welfare States'. In Emmenegger, P., Häusermann, S., Seeleib-Kaiser, M. and Palier, B. (eds) The Age of Dualization: The Changing Face of Inequality in Deindustrializing Societies, New York, Oxford University Press, pp. 73-99.

Emmenegger, P. (2009) 'Barriers to Entry: Insider/Outsider Politics and the Political Determinants of Job Security Regulations', Journal of European Social Policy, 19, 131-146.

Emmenegger, P. (2014) The Power to Dismiss: Trade Unions and the Regulation of Job Security, Oxford, Oxford University Press.

Emmenegger, P., Häusermann, S., Palier, B. and Seeleib-Kaiser, M. (2012) 'How We Grow Unequal'. In Emmenegger, P., Häusermann, S., Palier, B. and Seeleib-Kaiser, M. (eds) The Age of Dualization: The Changing Face of Inequality in Deindustrializing Societies, New York, Oxford University Press, pp. 3-26.

EUROSTAT (2014) LFS Series-Detailed Annual Survey Results. http://epp.eurostat.ec.europa.eu/ portal/page/portal/statistics/search_database.

Fong, C. (2001) 'Social Preferences, Self-interest, and the Demand for Redistribution', Journal of Public Economics, 82, 225-246.

Greenberg, E. S., Grunberg, L. and Daniel, K. (1996) 'Industrial Work and Political Participation: Beyond "Simple Spillover", Political Research Quarterly, 49, 305-330.

Green-Pedersen, C. and Van Kersbergen, K. (2002) "The Politics of the "Third Way": The Transformation of Social Democracy in Denmark and The Netherlands', Party Politics, 8, 507-524.

Hassel, A. (2014) 'The Paradox of Liberalization-Understanding Dualism and Recovery of the German Political Economy', British Journal of Industrial Relations, 52, 57-81.

Häusermann, S. and Schwander, H. (2012) 'Varieties of Dualization? Labor Market Segmentation and Insider-Outsider Divides across Regimes'. In Emmenegger, P., Häusermann, S., Palier, B. and Seeleib-Kaiser, M. (eds) The Age of Dualization: The Changing Face of Inequality in Deindustrializing Societies, New York, Oxford University Press, pp. 27-51.

Hayes, E. F. and Preacher, K. J. (2010) 'Quantifying and Testing Indirect Effects in Simple Mediation Models When the Constituent Paths Are Nonlinear', Multivariate Behavioral Research, 45, 627-660.

Hibbs, D. (1977) 'Political Parties and Macroeconomic Policy', American Political Science Review, 71, 1467-1487.

Hicks, R. and Tingley, D. (2011) 'Causal Mediation Analysis', Stata Journal, 11, 1-15.

Imai, K., Keele, L. and Tingley, D. (2010) 'A General Approach to Causal Mediation Analysis', Psychological Methods, 15, 309-334. 
Imai, K., Keele, L., Tingley, D. and Yamamoto, T. (2011) 'Unpacking the Black Box of Causality: Learning about Causal Mechanisms from Experimental and Observational Studies', American Political Science Review, 105, 765-789.

Iversen, T. and Soskice, D. (2001) 'An Asset Theory of Social Policy Preferences', American Political Science Review, 95, 875-893.

Jahoda, M., Elsaesser, T., Lazarsfeld, P. F., Reginall, J. and Zeisel, H. (1972) Marienthal: The Sociography of an Unemployed Community, London, Tavistock.

Kedar, O. (2005) 'When Moderate Voters Prefer Extreme Parties: Policy Balancing in Parliamentary Elections', American Political Science Review, 99, 185-199.

King, D. and Rueda, D. (2008) 'Cheap Labor: The New Politics of "Bread and Roses” in Industrial Democracies', Perspectives on Politics, 6, 279-297.

Korpi, W. (1983) The Democratic Class Struggle, London, Routledge and Kegan Paul.

Kriesi, H. (2014) 'The Populist Challenge', West European Politics, 37, 361-378.

Krosnick, J. A., Visser, P. S. and Harder, J. (2010) 'The Psychological Underpinnings of Political Behavior'. In Fiske, S. T., Gilbert, D. T. and Lindzey, G. (eds) Handbook of Social Psychology, 5th ed, Hoboken, NJ, Wiley, pp. 1288-1342.

Kselman, D. and Niou, E. (2011) 'Protest Voting in Plurality Elections: A Theory of Voter Signaling', Public Choice, 148, 395-418.

Lane, R. E. (1959) Political Life: Why People Get Involved in Politics, Glencoe, IL, Free Press.

Lindbeck, A. and Snower, D. J. (2001) 'Insiders versus Outsiders', Journal of Economic Perspectives, 15, 165-188.

Lindvall, J. and Rueda, D. (2014) 'The Insider-Outsider Dilemma', British Journal of Political Science, 44, 460-475.

Margalit, Y. (2013) 'Explaining Social Policy Preferences: Evidence from the Great Recession', American Political Science Review, 107, 80-103.

Marx, P. (2014) 'Labour Market Risks and Political Preferences: The Case of Temporary Employment', European Journal of Political Research, 53, 136-159.

Marx, P. (2015) 'The Insider-Outsider Divide and Economic Voting: Testing a New Theory with German Electoral Data', Socio-Economic Review, doi:10.1093/ser/mwu022.

Marx, P. and Picot, G. (2013) 'The Party Preferences of Atypical Workers in Germany', Journal of European Social Policy, 23, 164-178.

Marx, P. and Schumacher, G. (2013) 'Will to Power? Intra-party Conflict in Social Democratic Parties and the Choice for Neoliberal Policies in Germany, the Netherlands and Spain (19802010)', European Political Science Review, 5, 151-173.

OECD. (2012) OECD Employment Outlook 2012, Paris, OECD.

Palier, B. and Thelen, K. (2010) 'Institutionalizing Dualism: Complementarities and Change in France and Germany', Politics and Society, 38, 119-148.

Pateman, C. (1970) Participation and Democratic Theory, Cambridge, Cambridge University Press.

Paul, K. I. and Moser, K. (2009) 'Unemployment Impairs Mental Health: Meta-analyses', Journal of Vocational Behavior, 74, 264-282.

Plane, D. L. and Gershtenson, J. (2004) 'Candidates' Ideological Locations, Abstention, and Turnout in US Midterm Senate Elections', Political Behavior, 26, 69-93.

Plutzer, E. (2002) 'Becoming a Habitual Voter: Inertia, Resources, and Growth in Young Adulthood', American Political Science Review, 96, 41-56.

Prior, M. (2010) 'You've Either Got It or You Don't? The Stability of Political Interest over the Life Cycle', Journal of Politics, 72, 747-766.

Rehm, P. (2009) 'Risks and Redistribution: An Individual-level Analysis', Comparative Political Studies, 4, 855-881.

Rosenstone, S. J. (1982) 'Economic Adversity and Voter Turnout', American Journal of Political Science, 26, 25-46. 
Rosenstone, S. J. and Hansen, J. M. (1993) Mobilization, Participation, and Democracy in America, New York, Macmillan.

Rueda, D. (2005) 'Insider-Outsider Politics in Industrialized Democracies: The Challenge to Social Democratic Parties', American Political Science Review, 99, 61-74.

Saint-Paul, G. (1996) 'Exploring the Political Economy of Labour Market Institutions', Economic Policy, 11, 265-300.

Salverda, W. and Mayhew, K. (2009) 'Capitalist Economies and Wage Inequality', Oxford Review of Economic Policy, 25, 126-154.

Schlozman, K. L. and Verba, S. (1979) Injury to Insult: Unemployment, Class, and Political Response, Cambridge, MA, Harvard University Press.

Schur, L. (2003) 'Employment and the Creation of an Active Citizenry', British Journal of Industrial Relations, 41, 751-771.

Sobel, R. (1993) 'From Occupational Involvement to Political Participation: An Exploratory Analysis', Political Behavior, 15, 339-353.

Standing, G. (2011) The Precariat: The New Dangerous Class, London, Bloomsbury.

Sverke, M., Hellgren, J. and Näswall, K. (2002) 'No Security: A Meta-analysis and Review of Job Insecurity and its Consequences', Journal of Occupational Health Psychology, 7, 242-264.

Ulbig, S. G. and Funk, C. L. (1999) 'Conflict Avoidance and Political Participation', Political Behavior, 21, 265-282.

Verba, S., Schlozman, K. L. and Brady, H. E. (1995) Voice and Equality: Civic Voluntarism in American Politics, Cambridge, MA, Harvard University Press.

Visser, J. (2002) 'The First Part-time Economy in the World: A Model to Be Followed?', Journal of European Social Policy, 12, 23-42. 